\title{
Fatty acid stable isotope signatures of molluscs exposed to finfish farming outputs
}

\author{
S. M. Colombo ${ }^{1,3, *}$, C. C. Parrish ${ }^{1, *, * *}$, M. J. Whiticar ${ }^{2}$ \\ ${ }^{1}$ Department of Ocean Sciences, Memorial University of Newfoundland, St. John's, Newfoundland A1C 5S7, Canada \\ ${ }^{2}$ School of Earth and Ocean Sciences, University of Victoria, Victoria, British Columbia V8W 2Y2, Canada \\ ${ }^{3}$ Present address: Department of Chemistry and Biology, Ryerson University, Toronto, Ontario M5B 2K3, Canada
}

\begin{abstract}
Tracing the flow of nutrients from aquaculture operations to the surrounding biota is important for environmental monitoring and developing integrated aquaculture practices. A novel approach in this context, compound specific stable isotope analysis (CSIA) was used to trace fatty acid (FA) carbon in benthic invertebrates from multiple aquaculture sites in the Broughton Archipelago, British Columbia, Canada, up to $2500 \mathrm{~m}$ away from each site. We found that the carbon isotope ratios $\left(\delta^{13} \mathrm{C}\right)$ of certain FA in mussels and limpets were gradually ${ }^{13} \mathrm{C}$-enriched with increasing distance away from the site, suggesting that the farm contributed to more depleted isotopic signatures among organisms within the vicinity of the site. In mussels, the $\delta^{13} \mathrm{C}$ of $16: 2 \mathrm{n}-4$, 16:3n-4, 20:1n-9, 22:6n-3, saturated FA, the bacterial FA marker, and the overall weighted mean of FA became significantly more ${ }^{13} \mathrm{C}$-enriched with increasing distance from the farm $\left(\mathrm{r}^{2}>0.28\right.$, $\mathrm{p}<0.05)$. In limpets, the $\delta^{13} \mathrm{C}$ of $17: 0,18: 4 \mathrm{n}-3,20: 4 \mathrm{n}-3$ and the zooplankton FA marker became more enriched with distance away from the farm $\left(\mathrm{r}^{2}>0.37, \mathrm{p}<0.05\right)$. The $\delta^{13} \mathrm{C}$ of mussels was also influenced by location of the farm, regardless of distance from the site. Non-indigenous isotopic signatures, as a result of feed inputs, physical properties of the farm location, and other anthropogenic influences, likely contributed to the depleted signature of mussels and limpets within the vicinity of the farm. This study was the first to use CSIA to determine the uptake and movement of organic nutrients from aquaculture outputs to the surrounding ecosystem.
\end{abstract}

KEY WORDS: ${ }^{13} \mathrm{C} \cdot$ Biomarker $\cdot$ Fatty acids $\cdot$ Limpets $\cdot$ Molluscs $\cdot$ Mussels $\cdot$ Salmon $\cdot$ Stable isotopes

\section{INTRODUCTION}

The assimilation of aquaculture waste by surrounding biota is of interest from both environmental and regulatory perspectives (Sutherland et al. 2001, 2006, George \& Parrish 2015). Farmed fish consume the majority of feed pellets administered; however, 3 to $5 \%$ may not be consumed and settle beneath the farm or are carried out by effluent $(\mathrm{Wu}$ 1995, Reid et al. 2009). This has been mitigated in recent years with advances in feeding technologies and optimization of feed ingredients (Browdy et al. 2012, Hixson 2014). Nonetheless, the potential ac-

* These authors contributed equally to this work

** Corresponding author: cparrish@mun.ca cumulation of some level of waste material (excess feed and faeces) and resulting organic enrichment can influence the abundance and diversity of an existing benthic community (Henderson \& Ross 1995). Therefore, it is important to establish effects of fish farm nutrient waste on the surrounding ecosystem, particularly for the development of environmental standards, monitoring, and reporting (DFO 2015). The assimilation of excess feed and waste by commercially-relevant organisms (molluscs, bivalves, echinoderms, etc.) is also applicable from an integrated multi-trophic aquaculture perspective.

() The authors 2016. Open Access under Creative Commons by Attribution Licence. Use, distribution and reproduction are unrestricted. Authors and original publication must be credited. 
Stable isotope ratios are frequently used to evaluate the structure and dynamics of ecological communities. They are a powerful tool in animal ecology to analyse food webs (Post et al. 2002, Ruess et al. 2005, Budge et al. 2008). Differences in the atomic masses of different isotopes lead to isotope effects that regulate partitioning and reaction rates of the different isotopologues, resulting in isotope separation processes (Abrajano et al. 1994, Hayes 2001). Carbon isotope effects in food web transfers are relatively small, so there are only minor shifts in carbon isotope ratios as carbon flows through food webs $\left(\delta^{13} \mathrm{C}=\right.$ ca. $1 \%$ per level). As a consequence, differences in carbon isotope ratios of dietary sources are maintained and can be used to evaluate and distinguish sources and flows of carbon to an organism. Bulk carbon isotope ratios of plants are, dependent on factors such as whether the photosynthetic pathway uses bicarbonate, dissolved or free $\mathrm{CO}_{2}$, and ultimately from where the carbon is derived; those of aquatic plants are frequently distinct from terrestrial sources (Hobson 1999, Budge et al. 2008). As a result, the bulk carbon isotope composition of marine food webs is typically ${ }^{13} \mathrm{C}$-enriched compared to terrestrial food webs (Hobson 1999). Unfortunately, the diversity of carbon sources and the processes affecting them, e.g. partial pressure of carbon dioxide $\left(p \mathrm{CO}_{2}\right)$, temperature, salinity, etc., means that individual sources do not necessarily correspond to distinct endmember isotope compositions. In addition, mixtures of multiple sources and processes are under-constrained when using only bulk carbon isotopes (Fry \& Sherr 1984, Phillips \& Gregg 2003). This is most clearly reflected by animals that feed on different sources and trophic levels. Bulk stable isotopes (carbon and nitrogen), coupled with lipid and fatty acid (FA) composition, have previously been used as biomarkers to trace organic waste (excess feed and faeces) assimilated into organisms in surrounding areas from a farm site (Ye et al. 1991, Van Biesen \& Parrish 2005, Yokoyama et al. 2006, Redmond et al. 2010, George \& Parrish 2015). Relative proportions of natural food to aquaculture waste, sources of carbon in feed waste, physical properties of the farm, and location of the organisms relative to the farm, are all factors that affect the isotopic and FA signature of benthic organisms (Redmond et al. 2010, Callier et al. 2013, George \& Parrish 2015).

Some of the interpretative ambiguity associated with bulk isotopes can be ameliorated by using compound specific isotope analyses (CSIA; e.g. Collister et al. 1994). FA isotopic signatures can be used in food web studies as biochemical tracers to determine the transfer of FA from prey to predator based on their ${ }^{13} \mathrm{C} /{ }^{12} \mathrm{C}$ ratio (Budge et al. 2008). Compared with bulk values, the carbon isotope ratios of individual FAs offer a greater degree of differentiation and isotope tracking in food web studies (e.g. Budge et al. 2008). The advantage to using the compound specific stable isotope method is that it uniquely pairs bulk stable isotope and FA profiling, to allow for specific quantitative sourcing of each FA. Furthermore, combining individual FA composition with their stable isotope ratios is a more viable approach than bulk values to identify and differentiate sources of organic matter, either aquaculture waste or natural sources, that contribute to the diet of marine benthic invertebrates (De Troch et al. 2012).

Previously, George \& Parrish (2015) investigated the uptake of FA in the vicinity of Atlantic salmon Salmo salar net pens in the Broughton Archipelago in British Columbia, Canada. Tracing the flow of FA away from the farm sites showed differences in the proportion of FA (in macroinvertebrates) as a function of distance. In tandem with the same samples as in George \& Parrish (2015), we used CSIA on FAs to trace the flow of nutrients from the net pens of salmon farms, at multiple locations up to $2400 \mathrm{~m}$ away from the farm, in 2 representative benthic invertebrates. To our knowledge, this is the first application of CSIA to trace FA flow from an aquaculture system.

\section{MATERIALS AND METHODS}

\section{Sampling}

Samples were collected by hand in benthic and intertidal zones on the periphery of 5 Atlantic salmon aquaculture locations in British Columbia. Multiple farms were sampled to investigate site effects, and to form a more statistically robust model ( $\mathrm{n}=5$ farms). Sampling occurred in the vicinity of salmon farms in the Broughton Archipelago (at Blunden Pass, Upper Retreat Pass, Betty Cove, and Sir Edmund Bay), off Vancouver Island's northeast coast from April to May 2003, and in Clayoquot Sound (Bedwell Sound), off the western coast of Vancouver Island in June 2004. Mollusc sampling at each station included up to 8 mussels (Mytilus edulis) and 4 limpets (Acmaea testudinalis). Sampling was carried out along linear transects aligned towards open water at increasing intervals of distance away from the source. Samples were taken at multiple distances away from 4 salmon farms in the Broughton Archipelago (at 75, 92, 200, $300,400,500,775,1483$ and $1950 \mathrm{~m}$ ) and 1 salmon farm 
in Clayoquot Sound (at 306, 371, 518, 727, 967, 1686 and $2358 \mathrm{~m}$ ). Additional details regarding farms and locations can be found in George \& Parrish (2015).

\section{Sample processing}

Samples were stored in large plastic bags at $-20^{\circ} \mathrm{C}$, then shipped to the laboratory on dry ice and stored at $-80^{\circ} \mathrm{C}$ upon arrival. Invertebrates were removed from their shells, weighed, and placed in test tubes with chloroform and stored at $-20^{\circ} \mathrm{C}$ under nitrogen gas, with caps sealed with Teflon tape.

\section{Chemical analyses}

Lipid extraction followed Parrish (1999) based on Folch et al. (1957). The extracts were derivatized to FA methyl esters (FAMEs) using $14 \% \mathrm{BF}_{3} / \mathrm{MeOH}$ for $1.5 \mathrm{~h}$ at $85^{\circ} \mathrm{C}$, with agitation at $45 \mathrm{~min}$ (Parrish 1999). The FA composition of invertebrates in this study was previously published in George \& Parrish (2015).

The resulting FAMEs were analyzed for compound specific stable isotopes by gas chromatograph-combustion-isotope ratio mass spectrometry (GC-CIRMS; Veefkind 2003). FAMEs were separated on a SUPELCO SPB-PUFA column $(30 \mathrm{~m} \times 0.25 \mathrm{~mm}$ internal diameter $\times 0.2 \mu \mathrm{m}$ film) in a Varian 3400 gas chromatograph, combusted online in a $\mathrm{Cu} / \mathrm{Pt}$ wire microcombustion oven at $850^{\circ} \mathrm{C}$ then inlet into a Finnigan MAT 252 isotope ratio mass spectrometer. Carbon isotope ratios are reported in the usual delta notation $\left(\delta^{13} \mathrm{C}\right)$ relative to the Vienna Pee Dee Belemnite (VPDB) standard as follows:

$$
\delta^{13} \mathrm{C}_{\mathrm{X}}=\left[\frac{{ }^{13} \mathrm{C} /{ }^{12} \mathrm{C}_{\text {sample }}}{{ }^{13} \mathrm{C} /{ }^{12} \mathrm{C}_{\mathrm{VPDB}}}-1\right] \cdot 10^{3}
$$

An aliquot of the methanol used during methylation of FA was analyzed for $\delta^{13} \mathrm{C}$ composition. To correct for the additional methyl group added to the FAs during transesterification, the $\delta^{13} \mathrm{C}$ of methanol was predetermined and subtracted from the $\delta^{13} \mathrm{C}$ of FAME using the mass balance:

$$
\delta^{13} \mathrm{C}=(\mathrm{n}+1)\left[\delta^{13} \mathrm{C}_{\mathrm{FAME}}\right]-\mathrm{n}\left[\delta^{13} \mathrm{C}_{\mathrm{FFA}}\right]
$$

where $\mathrm{n}$ is the number of $\mathrm{C}$ atoms in the FA (Budge et al. 2011). All FAME data were corrected for the contribution of this methyl group from this equation. The overall weighted average was calculated by multiplying the $\delta^{13} \mathrm{C}$ for each FA by the FA concentration, so that a dominant FA had a greater influence on the overall mean than a minor one.

\section{Statistical analyses}

Linear regression analyses were used to relate fatty acid isotope ratios $\left(\delta^{13} \mathrm{C}_{\mathrm{FA}}\right.$, response variable) with distance from the farms (explanatory variable) in mussels, limpets, and mussel and limpet pooled data. The farm locations were pooled for linear regression analyses. Multiple sampling points occurred at the same distances for 2 or more farm sites; however, some sampling points were only represented at 1 farm site (i.e. multiple samples were not collected at all distances at every farm). In this particular model, individual farm site location was deemed less important than the effect of distance from the farm on isotope ratios. Logarithmic regressions were also used to relate FA isotope ratios with distance; however, while they did show significant relationships, fewer FAs showed significant relationships with distance using logarithms. Thus, linear regressions gave better fits to explain the relationships among FA $\delta^{13} \mathrm{C}$ values and distance from the farm. In addition to the linear regression models, piecewise 2-segmented regressions were used to determine if there was a distinct change or breakpoint in $\delta^{13} \mathrm{C}$ at a specific distance away from the farm, as in George \& Parrish (2015).

In order to evaluate if farm site was a factor in our linear models, an analysis of covariance (ANCOVA) was performed. In this case, the relationship between isotope ratios (response variable) and distance (explanatory variable) was evaluated with consideration of farm site (categorical variable). The effect of distance and/or farm site was considered significant when $\mathrm{p}<0.05$ for both linear regression and ANCOVA models.

All regressions were conducted in SigmaPlot 11.0 (Systat Software), and ANCOVA was conducted in Minitab (Minitab 16 Statistical Software). The normality, homogeneity and independence of residuals were considered to evaluate the data and appropriateness of the statistical model used.

\section{RESULTS}

For mussels, positive linear relationships $(\mathrm{p}<0.05$; Table 1) were observed between distance and the overall $\delta^{13} \mathrm{C}$ weighted average of all FA (Fig. 1a), and the individual $\delta^{13} \mathrm{C}$ signatures of $16: 2 \mathrm{n}-4,16: 3 \mathrm{n}-4$, 20:1n-9 and 22:6n-3 (Fig. 1b), as well as the sum of saturated FA, and the bacterial FA marker. An observed bimodal distribution between distal and proximal $\delta^{13} \mathrm{C}$ was highlighted in 2 zones for both the 
Table 1. Linear regression results from significant relationships $(p<0.05)$ among $\delta^{13} \mathrm{C}$ of fatty acids (FA) in mussels and limpets and distance $(z)$ away from aquaculture sites near Vancouver Island. 'Overall $\delta^{13} \mathrm{C}$ mean' is the mean $\delta^{13} \mathrm{C}$ of all identified FA weighted by FA concentration; NMID: $\mathrm{C}_{22}$ non-methylene-interrupted dienes

\begin{tabular}{|lccrr|}
\hline Fatty acid $\left(\delta^{13} \mathrm{C}\right)$ & $\mathrm{n}$ & Linear regression equation & $\mathrm{r}^{2}$ & $\mathrm{p}$-value \\
\hline Mussels & & & & \\
$16: 2 \mathrm{n}-4$ & 10 & $y=-25.9 \%+(0.0024 z)$ & 0.42 & 0.04 \\
$16: 3 \mathrm{n}-4$ & 8 & $y=-26.5 \%+(0.0019 z)$ & 0.50 & 0.04 \\
$20: 1 \mathrm{n}-9$ & 19 & $y=-26.2 \%+(0.0012 z)$ & 0.26 & 0.03 \\
$22: 6 \mathrm{n}-3$ & 21 & $y=-24.7 \%+(0.0010 z)$ & 0.28 & 0.01 \\
$\sum$ saturated FA & 21 & $y=-25.7 \%+(0.0010 z)$ & 0.26 & 0.04 \\
$\sum$ bacterial FA & 21 & $y=-26.8 \%+(0.0002 z)$ & 0.34 & 0.02 \\
Overall $\delta^{13}$ C mean & 21 & $y=-26.1 \%+(0.0009 z)$ & 0.21 & 0.04 \\
Limpets & & & & \\
$17: 0$ & 8 & $y=-23.6 \%+(0.0018 z)$ & 0.55 & 0.04 \\
$18: 4 \mathrm{n}-3$ & 7 & $y=-22.9 \%+(0.0013 z)$ & 0.67 & 0.03 \\
$20: 4 \mathrm{n}-3$ & 8 & $y=-23.3 \%+(0.0019 z)$ & 0.37 & 0.02 \\
Zooplankton & 12 & $y=-23.5 \%+(0.0016 z)$ & 0.37 & 0.04 \\
NMID & 6 & $y=-19.8 \%-(0.0032 z)$ & 0.97 & $<0.001$ \\
Combined & & & & \\
$16: 4 \mathrm{n}-3$ & 21 & $y=-31.6 \%+(0.0050 z)$ & 0.21 & 0.04 \\
$\sum$ saturated FA & 32 & $y=-30.5 \%+(0.0050 z)$ & 0.13 & 0.04 \\
$\sum$ bacterial FA & 32 & $y=-24.9 \%+(0.0012 z)$ & 0.20 & 0.02 \\
\hline
\end{tabular}

overall and 22:6n-3 $\delta^{13} \mathrm{C}$ (Fig. 1a,b). An approximate mixing line was used to connect the distal and proximal endmember $\delta^{13} \mathrm{C}$ values for the overall $\delta^{13} \mathrm{C}$ mean and 22:6n-3. The mean $\delta^{13} \mathrm{C}$ that was not influenced by farm inputs was $-23.1 \%$ for $22: 6 n-3$ and $-24.3 \%$ for the overall weighted mean. Farm site was a significant categorical factor in the ANCOVA model for all FA isotopic signatures, except 16:2n-4 and the bacterial FA marker. See Table S1 in the Supplement at www.int-res.com/articles/suppl/q008 p611_supp.pdf for $\delta^{13} \mathrm{C}$ values at each location.

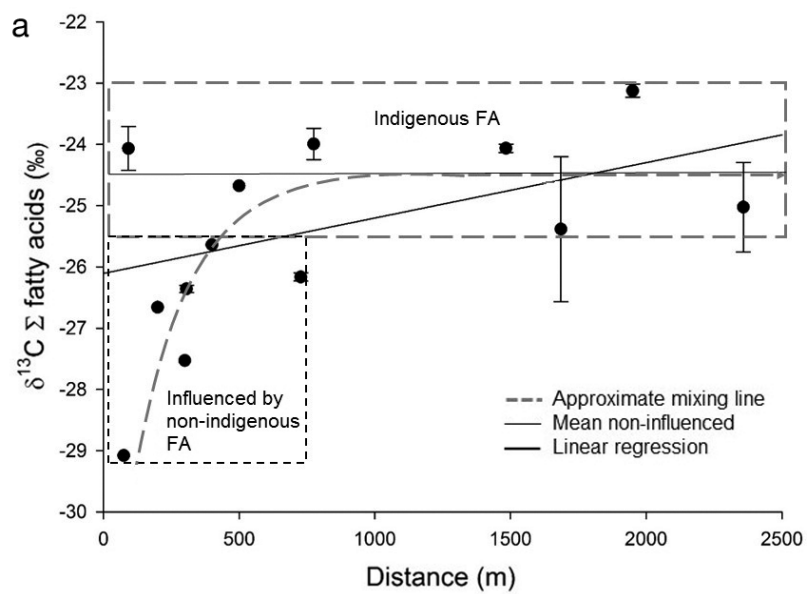

For limpets, positive linear relationships $(p<0.05$; Table 1$)$ were observed between distance and the $\delta^{13} \mathrm{C}$ signatures of $17: 0$, $18: 4 n-3,20: 4 n-3$, and the zooplankton FA marker. The isotope ratios of $\mathrm{C}_{22}$ nonmethylene-interrupted dienes (NMID) were negatively related to distance. Farm site was only a significant factor for 18:2n-6 $(p=0.004)$ and the bacterial FA marker $(p=0.004)$ in the ANCOVA model. See Table S2 in the Supplement for $\delta^{13} \mathrm{C}$ values at each location.

For mussels and limpet data combined, positive linear relationships $(\mathrm{p}<0.05$; Table 1) with distance were observed with the $\delta^{13} \mathrm{C}$ values of $16: 4 \mathrm{n}-3$, the bacterial FA marker, and sum of saturated FA. Farm site was a significant categorical factor for $20: 1 \mathrm{n}-9(\mathrm{p}=0.001), 17: 0(\mathrm{p}=0.001)$, sum of monounsaturated FA ( $p=0.008)$ and bacterial FA marker $(p=0.024)$. See Table S3 in the Supplement for $\delta^{13} \mathrm{C}$ values at each location.

Piecewise (2-segmented) regressions were not significant for any FA $\delta^{13} \mathrm{C}$ in mussels or limpets.

\section{DISCUSSION}

We investigated the nutritional influence from 5 different salmon farm operations on the surrounding environment by tracing the flow of $\delta^{13} \mathrm{C}$ FA. We found that the $\delta^{13} \mathrm{C}$ of certain FA in molluscs gradually changed with increasing distance away from

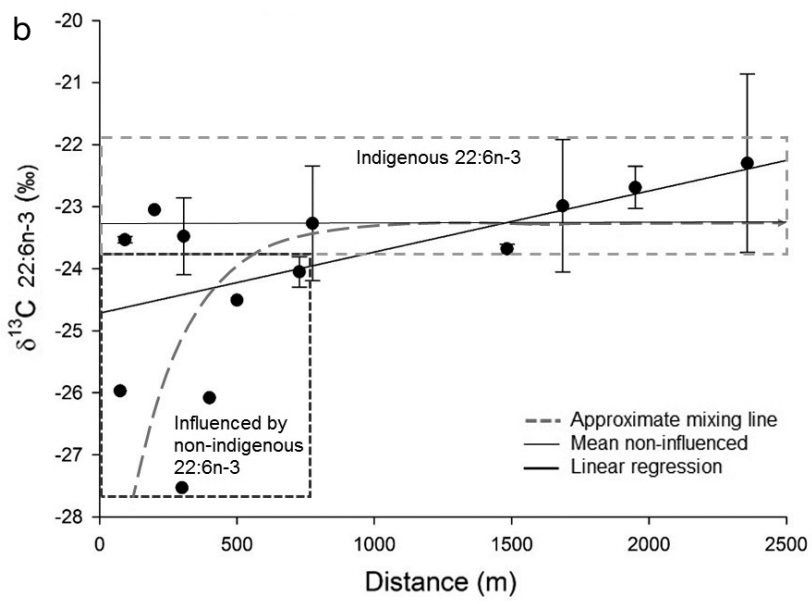

Fig. 1. Isotopic signature (\%) of (a) overall $\delta^{13} \mathrm{C}$ weighted mean, and (b) 22:6n-3 in mussels with increasing distance from salmon cage sites. The plots show mean $\delta^{13} \mathrm{C}$ ( \pm standard deviation) as linear functions with regression analyses performed on raw data. Dashed-box zones highlight observed bimodal scenarios in $\delta^{13} \mathrm{C}$ between distal and proximal locations, with an approximate mixing line estimated as the bimodal connection between endmember $\delta^{13} \mathrm{C}$ 
salmon net pens around Vancouver Island, British Columbia.

The farm's presence contributed to a FA-specific carbon isotope shift in mussels and limpets. Generally, they were relatively ${ }^{13} \mathrm{C}$-depleted within the vicinity of the farm site, and ${ }^{13} \mathrm{C}$-enriched with increasing distance from the farm. The overall ${ }^{13} \mathrm{C}$ depleted signature of invertebrates within the vicinity of the farm together with the trajectory of ${ }^{13} \mathrm{C}$ enrichment away from the farm are both evidence that the diet of molluscs near the farms was different to their natural diet in less impacted sites. It also indicates that food sources from the farm influenced sources of carbon consumed, especially close to the farms. While the relationship between $\delta^{13} \mathrm{C} F A$ and distance was linear, a bimodal distribution in $\delta^{13} \mathrm{C}$ with increasing distance was observed (Fig. 1a,b) in which there appeared to be minimal influence of the farms on the $\delta^{13} \mathrm{C}$ beyond a certain distance. This suggests a maximum detectable distance estimation of $\sim 750 \mathrm{~m}$ for fish farm influence on natural systems. New or non-indigenous isotopic signatures (as a result of feed inputs), as well as the physical properties of the farm location, may have contributed to the depleted signature of mussels and limpets within the vicinity of the farm. Mussels and limpets did not appear to be affected differently, despite the difference in feeding habits between these molluscs (filter feeder vs. grazer).

Our results suggest that salmon feed/faeces released in the environment had the most significant impact on the isotope signatures of molluscs close to the farm. In comparison to the inputs that were taken up by benthic invertebrates within the vicinity of the farm, the dietary items of the molluscs away from the farm likely consists of phytoplankton and/or detritus, which have a more ${ }^{13} \mathrm{C}$-enriched signature. For example, the $\delta^{13} \mathrm{C}$ of $22: 6 \mathrm{n}-3$ of mussels at the closest sampling point within the farm's vicinity (at $75 \mathrm{~m}$ : $-26.1 \%$ ) and the furthest point sampled away from the farm (at $2400 \mathrm{~m}:-22.2 \%$ ) coincides with the more depleted $\delta^{13} \mathrm{C}$ of $22: 6 \mathrm{n}-3$ in the feed $(-23.8 \%$; see Table S4 in the Supplement) and the more enriched $\delta^{13} \mathrm{C}$ in phytoplankton (-22.2\%; Budge et al. 2001). This indicates the influence of these different dietary sources as a function of the aquaculture site. New (or non-indigenous) carbon sources from the feed were more depleted in ${ }^{13} \mathrm{C}$. This may be related to the utilization of feed with fish meals and fish oils from different locations (with different $\delta^{13} \mathrm{C}$ values), and/or terrestrial-based ingredients in the feed with ${ }^{13} \mathrm{C}$-depleted isotopic signature compared to marinebased ingredients (e.g. Hixson et al. 2014).
We also determined that farm site-influenced isotopic signatures. In mussels, farm site-influenced all FA isotopic signatures, except for $16: 2 \mathrm{n}-4$ and the bacterial marker, which only showed a relationship with distance. In FA that did not show a relationship with distance, but differed due to farm site, the linear relationship with distance may have been masked by combining the farm sites. In limpets, however, farm site was only a factor for the $\delta^{13} \mathrm{C}$ of $18: 2 \mathrm{n}-6$ and the bacterial marker, both of which also changed as a function of distance. For pooled mussel and limpet data, the isotopic signature of the bacterial marker was influenced by both distance and farm site, suggesting that these are both factors that determine the bacterial communities within benthic invertebrates. The specific location of the farm can also influence isotope ratios. For example, there are consistent differences in the $\delta^{13} \mathrm{C}$ of littoral and pelagic zones, and this can influence the relative proportions of natural food and farm inputs (Post et al. 2002, Redmond et al. 2010). Furthermore, current velocity and water depth are fundamental factors in dispersion, mixing, and loading of particulate wastes from farms (Yokoyama et al. 2006). Therefore, the oceanographic properties of a farm site can also influence isotope signatures.

Mussels and limpets showed evidence of bacterial FA in their tissues (George \& Parrish 2015), and our study found that the $\delta^{13} \mathrm{C}$ of this marker became more ${ }^{13} \mathrm{C}$-enriched away from the farm site. This indicates a difference in bacterial community composition as a function of distance, influenced by farm activities. Anaerobic conditions (Kohring et al. 1994), presence of methane (Pistocchi et al. 2005), solid wastes (Sutherland et al. 2001), and antibiotics (Kim et al. 2004) can all influence bacterial community composition. Interestingly, George \& Parrish (2015) found that the bacterial FA marker was proportionally lower within the vicinity of the farm, coinciding with our conclusion that a lower $\delta^{13} \mathrm{C}$ value indicates higher bacterial counts in mussels with increasing distance away from the farm. In addition, reduced oxygen at high organic settlement areas may have prevented certain bacterial growth.

We found that aquaculture outputs influenced the $\delta^{13} \mathrm{C}$ FA composition of molluscs in a linear fit. CSIA permits us to distinguish sources for the same compound, information that could not be obtained only from molecular and bulk stable isotope composition. As FA (or groups of FA) are often used as biomarkers and indices, the use of CSIA yields more specific information regarding their dietary source in an organism. Although our study showed relatively few significant shifts with distance, this can be a useful 
tool in other studies, and can help in site selection, environmental monitoring, and regulating aquaculture effluent. Future research may relate impacts (such as benthic sulfides) with nutrient-related data, such as CSIA to create new indices of aquaculture impacts. From a multi-trophic aquaculture perspective, our results confirm that molluscs take up nutrients directly from farm outputs within the vicinity of the farm, despite availability of FA from natural sources.

Acknowledgements. This work was funded through a Natural Science and Engineering Research Council of Canada Strategic Project Grant. We are very grateful to Paul Eby for assistance with the isotope measurements by Continuous Flow-Isotope Ratio Mass Spectrometer. The authors also thank Dr. Gregor Reid and 2 anonymous reviewers for their valuable comments which helped improve the manuscript.

\section{LITERATURE CITED}

Abrajano TA, Murphy DE, Fang J, Comet P, Brooks JM (1994) ${ }^{13} \mathrm{C} /{ }^{12} \mathrm{C}$ ratios in individual fatty acids of marine mytilids with and without bacterial symbionts. Org Geochem 21:611-617

Browdy CL, Hulata G, Liu Z, Allan GL and others (2012) Novel and emerging technologies: Can they contribute to improving aquaculture sustainability? In: Subasinghe RP, Arthur JR, Bartley DM, De Silva SS and others (eds) Farming the waters for people and food. Proc Global Conference on Aquaculture 2010, Phuket, 22-25 September 2010. FAO, Rome and NACA, Bangkok, p 149-191

Budge SM, Parrish CC, McKenzie CH (2001) Fatty acid composition of phytoplankton, settling particulate matter and sediments at a sheltered bivalve aquaculture site. Mar Chem 76:285-303

Budge SM, Wooler MJ, Springer AM, Iverson SJ, McRoy CP, Divoky GJ (2008) Tracing carbon flow in an arctic marine food web using fatty acid-stable isotope analysis. Oecologia 157:117-129

Budge SM, Wang SW, Hollmén TE, Wooller MJ (2011) Carbon isotopic fractionation in eider adipose tissue varies with fatty acid structure: implications for trophic studies. J Exp Biol 214:3790-3800

> Callier MD, Lefebvre S, Dunagan MK, Bataille MP, Coughlan J, Crowe TP (2013) Shift in benthic assemblages and organisms' diet at salmon farms: community structure and stable isotope analyses. Mar Ecol Prog Ser 483: 153-167

Collister JW, Rieley G, Stern BG, Eglinton GB, Fry B (1994) Compound specific $\delta^{13} \mathrm{C}$ analyses of leaf lipids from plants with differing carbon dioxide metabolisms. Org Geochem 21:619-627

> De Troch M, Boekx P, Cnudde C, Van Gansbeke D, Vanreusel A, Vincx M, Caramujo MJ (2012) Bioconversion of fatty acids at the basis of marine food webs: insights from a compound-specific stable isotope analysis. Mar Ecol Prog Ser 465:53-67

DFO (Fisheries and Oceans Canada) (2015) Aquaculture monitoring standards. Fisheries and Oceans Canada, Ottawa, p 1-12
Folch J, Lees M, Sloane-Stanley GH (1957) A simple method for the isolation and purification of total lipids from animal tissues. J Biol Chem 226:497-509

Fry B, Sherr EB (1984) $\delta^{13} \mathrm{C}$ measurements as indicators of carbon flow in marine and freshwater ecosystems. Contrib Mar Sci 27:13-47

> George EM, Parrish CC (2015) Invertebrate uptake of lipids in the vicinity of Atlantic salmon (Salmo salar) aquaculture sites in British Columbia. Aquacult Res 46: 1044-1065

> Hayes JM (2001) Fractionation of carbon and hydrogen isotopes in biosynthetic processes. Rev Mineral Geochem 43:225-277

Henderson AR, Ross DJ (1995) Use of macrobenthic infaunal communities in the monitoring and control of impact of marine cage fish farming. Aquacult Res 26:659-678

Hixson SM (2014) Fish nutrition and current issues in aquaculture: the balance in providing safe and nutritious seafood, in an environmentally sustainable manner. Aquacult Res Dev 5:3

> Hixson SM, Parrish CC, Anderson DM (2014) Changes in tissue lipid and fatty acid composition of farmed rainbow trout in response to dietary camelina oil as a replacement of fish oil. Lipids 49:97-111

Hobson KA (1999) Tracing origins and migration of wildlife using stable isotopes: a review. Oecologia 120:314-326

Kim SR, Nonaka L, Suzuki S (2004) Occurrence of tetracycline resistance genes tet(M) and tet(S) in bacteria from marine aquaculture sites. FEMS Microbiol Lett 237: $147-156$

Kohring LL, Ringelberg DB, Devereux R, Stahl DA, Mittelman MW, White DC (1994) Comparison of phylogenetic relationships based on phospholipid fatty acid profiles and ribosomal RNA sequence similarities among dissimilatory sulfate-reducing bacteria. FEMS Microbiol Lett 119:303-308

Parrish CC (1999) Determination of total lipid, lipid classes and fatty acids in aquatic samples. In: Arts MT, Wainman BC (eds) Lipids in freshwater ecosystems. Springer, New York, NY, p 4-20

Phillips DL, Gregg JW (2003) Source partitioning using stable isotopes: coping with too many sources. Oecologia 136:261-269

Pistocchi R, Trigari G, Serrazanetti GP, Taddei P and others (2005) Chemical and biochemical parameters of cultured diatoms and bacteria from the Adriatic Sea as possible biomarkers of mucilage production. Sci Total Environ 353:287-299

> Post DM (2002) Using stable isotopes to estimate trophic position: models, methods, and assumptions. Ecology 83:703-718

> Redmond KJ, Magnesen T, Kupka Hansen P, Strand $\varnothing$, Meier S (2010) Stable isotopes and fatty acids as tracers of the assimilation of salmon fish feed in blue mussels (Mytilus edulis). Aquaculture 298:202-210

> Reid GK, Liutkus M, Robinson SMC, Chopin TR and others (2009) A review of the biophysical properties of salmonid faeces: implications for aquaculture waste dispersal models and integrated multi-trophic aquaculture. Aquacult Res 40:257-273

Ruess L, Tiunov A, Haubert D, Richnow HH, Häggblom MM, Scheu S (2005) Carbon stable isotope fractionation and trophic transfer of fatty acids in fungal based soil food chains. Soil Biol Biochem 37:945-953 
Sutherland TF, Levings CD, McPhie R, Petersen SA, Knapp W (2006) A benthic study examining the relationship between sediment properties and faunal groups observed at Sir Edmund Bay, British Columbia. Can Tech Rep 2631, Fisheries and Oceans Canada, West Vancouver Sutherland TF, Martin AJ, Levings CD (2001) Characterization of suspended particulate matter surrounding a salmonid net-pen in the Broughton Archipelago, British Columbia. ICES J Mar Sci 58:404-410

- Van Biesen G, Parrish CC (2005) Long-chain monounsaturated fatty acids as biomarkers for the dispersal of organic waste from a fish enclosure. Mar Environ Res 60: $375-388$

Editorial responsibility: Gianluca Sará, Palermo, Italy
Veefkind RJ (2003) Carbon isotope ratios and composition of fatty acids: tags and trophic markers in pelagic organisms. PhD thesis, University of Victoria

Wu R (1995) The environmental impact of marine fish culture: towards a sustainable future. Mar Pollut Bull 31: 159-166

> Ye L, Ritz D, Fenton G, Lewis M (1991) Tracing the influence on sediments of organic waste from a salmonid farm using stable isotope analysis. J Exp Mar Biol Ecol 145:161-174

Yokoyama H, Abo K, Ishihi Y (2006) Quantifying aquaculture-derived organic matter in the sediment in and around a coastal fish farm using stable and nitrogen isotope ratios. Aquaculture 254:411-425

Submitted: April 4, 2016; Accepted: September 27, 2016 Proofs received from author(s): October 18, 2016 